\title{
¿

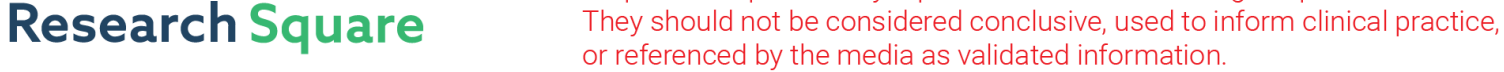 \\ Decontamination methods for respiratory protection mask model N95: a rapid review
}

\section{Livia Fernandes Probst}

Universidade Federal de Mato Grosso do Sul

\section{Ana Tereza Gomes Guerrero}

Fundação Oswaldo Cruz

Andréia Insabralde de Queiroz Cardoso

Universidade Federal de Mato Grosso do Sul

Antônio José Grande

Universidade Estadual de Mato Grosso do Sul

Mariana Garcia Croda

Universidade Federal de Mato Grosso do Sul

James Venturini

Universidade Federal de Mato Grosso do Sul

Maria Cristina de Camargo Fonseca

Universidade Estadual de Feira de Santana

Anamaria Mello Miranda Paniago

Universidade Federal de Mato Grosso do Sul

Jorge Otávio Maia Barreto ( $\sim$ jorgeomaia@hotmail.com )

Fundacao Oswaldo Cruz

Sandra Maria do Valle Leone de Oliveira ( $\square$ sandra.leone@ufms.br)

Universidade Federal de Mato Grosso do Sul https://orcid.org/0000-0002-8960-6716

\section{Research}

Keywords: Decontamination, Disinfection, Sterilization, Equipment reuse, N95 respirator, COVID-19

Posted Date: November 12th, 2020

DOI: https://doi.org/10.21203/rs.3.rs-38933/v2

License: (9) This work is licensed under a Creative Commons Attribution 4.0 International License.

Read Full License 
Version of Record: A version of this preprint was published at Systematic Reviews on August 7th, 2021. See the published version at https://doi.org/10.1186/s13643-021-01742-1. 


\section{Abstract}

Background: N95 respiratory protection masks are used by healthcare professionals to prevent contamination with infectious microorganisms transmitted by droplets or aerosols.

Methods: We conducted a rapid review of the literature analyzing the effectiveness of decontamination methods for mask reuse. The review was carried out in September 2020 using a simplification of the formal systematic review process, which simplified the stages of a complete systematic review, including the exclusion of an assessment of study methodology.

Results: A total of 563 articles were retrieved of which 48 laboratory-based studies were selected. Fifteen decontamination methods were included in the studies. Hydrogen peroxide was evaluated by 19 laboratory studies, ultraviolet germicidal irradiation by 21 , ethylene oxide by 4 , dry heat by 11 , moist heat by 9 , ethanol by 5 , isopropanol solution by 2 , microwave oven by 11 , sodium hypochlorite by 10 , autoclave by 7 , electric rice cooker by 3 , cleaning wipes by 1 , bar soap and water 1 , multi-Purpose HighLevel Disinfection Cabinet by 1 and chlorine dioxide by 1 . Five methods appear promising: hydrogen peroxide vapor, ultraviolet irradiation, dry heat, wet heat/pasteurization, and microwave ovens.

Conclusions: Positive results should be considered with caution as they represent a small number of studies, reflect ideal laboratory conditions, and may have limited applicability in realistic situations and for health systems.

\section{Background}

The world is facing a pandemic of coronavirus disease (COVID-19), caused by severe acute respiratory syndrome coronavirus 2 (SARS-CoV-2). ${ }^{1-5}$ Respiratory transmission routes of these viruses between humans are well established and based on transport via aerosols, droplets, secretions or through direct contact with nasal mucosa. ${ }^{6}$

The use of respiratory protection masks, particularly model N95, by health professionals in the care of infected patients is recommended in aerosol-producing procedures (tracheal intubation, non-invasive ventilation, tracheotomy, cardiopulmonary resuscitation, manual ventilation, before intubation, collections of nasotracheal secretions and bronchoscopies) and the recommendation is to discard it after close contact with a patient (single-use).$^{7-9}$

During the current COVID-19 pandemic, governments have found it difficult to acquire adequate amounts of Personal Protection Equipment (PPE) including respiratory protection masks; this has been accompanied by a high level of infection of health professionals on the front lines of services. ${ }^{10-14}$ The COVID-19 pandemic has not only exposed the need for health professionals to have access to the most effective PPE, it has exposed the inability of many health systems to meet this need. In this context and with the goal of enabling reuse of protective masks, research on alternatives for their decontamination has been carried out. 
The recent epidemics and pandemics caused by respiratory viruses have been characterized by a shortage of N95 masks. In this scenario health care professionals seek alternatives, including the decontamination and reuse of PPE. ${ }^{15}$ However, there is concern about disease transmission as there are no best practices for mask decontamination and reuse. ${ }^{16}$ In critical circumstances, rapid analyses are recommended by $\mathrm{WHO}^{17}$ to provide guidance for timely decision making. This quick review examines the knowledge base on the effectiveness and safety of decontamination methods for N95 masks for reuse as protection against COVID-19 and other respiratory viruses. A recent systematic review evaluated the efficacy and safety of N95 mask disinfection methods with emphasis on decontamination from SARSCoV- $2^{18}$. Nevertheless, it must be considered that we will continue to observe the emergence of new viruses and infections ${ }^{19}$, and concerns about efficacy and safety of methods of decontamination of personal protective equipment for will remain until more scientific evidence emerges. Furthermore, recently the likelihood of a second wave of COVID-19 points to the recurrence of previous problems and the need for planning for stockpiling and handling of personal protective equipment. ${ }^{20,21}$

\section{Methods}

Search strategy and selection criteria

This rapid review follows the principles outlined by Haby et $\mathrm{al}^{22}$, which simplify the stages of a complete systematic review, including the exclusion of an assessment of the risk of bias in the included studies and . According to these principles, we developed a specific protocol for this study (Supplementary material 1). Searches were conducted on Medline, Cochrane Library and EMBASE databases on September 25, 2020. Search terms were related to decontamination (e.g., "Sterilization", "Disinfection" and "Decontamination"), reuse (e.g., "Equipment Reuse" and "Reuse"), device failure ("Equipment Failure") and masks (e.g., "N95" and "filtering facepiece respirators"). Articles were included that evaluated methods for decontamination of N95 masks for reuse and whose outcome was the effectiveness, safety, maintenance of protection or filtering characteristics of the evaluated decontamination method. The language and date of publication of references was not an exclusion criterion.

\section{Results}

Search results and study selection process

The complete search strategies can be found in Table 1 of Supplementary material 2. Initial searches retrieved 552 articles (Medline: 381, Cochrane: 52 and EMBASE: 119). Manual searches detected 11 additional publications. Mendeley citation management software was used for automatic removal of duplicate articles, remaining 301 studies. Two reviewers (LFP and AIQC) independently screened the 301 studies using the Rayyan systematic review application to screen abstracts and titles. ${ }^{23}$ Of these, 240 
were excluded for not meeting the inclusion criteria. The full texts of 61 studies were screened by two reviewers (LFP and AIQC) and thirteen additional studies were excluded. Excluded full text studies and the reasons for exclusion are listed in Table 2 of Supplementary material 3 . At the end, 48 studies were selected for the full review process (Figure 1).

\section{Data extraction}

Two reviewers (LFP and AIQC) independently used a pre-specified data extraction sheet form designed to obtain the specific data required for this review. The data extracted from the primary studies were: data related to the author, year, study objective, intervention, comparator, commercial mask model, target microorganism, results and conclusions of the study authors, limitations and detailed description of the decontamination process making its reproducibility in other scenarios possible.

\section{Characterization of the included studies}

The specifics of each study (cycles, temperatures, protocols, densities, exposure time, technology used and results) are described in Table 3 of Supplementary material 4 and the differences before and after decontamination are shown in Table 4 of Supplementary Material 5 for outcomes: filter aerosol penetration, filter airflow resistance and filtration efficiency. Results of the studies were summarized based on decontamination method and results for the two issues: ${ }^{24}$

1. Whether the device maintains its structural characteristics and provides an adequate level of protection after the decontamination method, without any risk of exposure for the health professional to exposure to inhalable chemical residues that may have remained after the method used. The penetration of $0.3 \mu \mathrm{m}$ (aerodynamic mass mean diameter) of sodium chloride aerosols aerosol particles through a certified N95 respirator cannot exceed $5 \% .{ }^{25}$

2. Whether the decontamination method used was effective in reducing or completely eliminating the infectious capacity of the target organism without any risk of exposure for the health professional to contamination.

Fifteen methods were assessed in the 48 papers: hydrogen peroxide, ultraviolet irradiation, ethylene oxide, dry heat, moist heat/pasteurization, ethanol, isopropanol solution, microwaving, sodium hypochlorite ( $\mathrm{NaClO}$ ), autoclaving, electric rice cooker, cleaning wipes, bar soap and water, Multi-Purpose High-Level Disinfection Cabinet (Altapure, Mequon, WI) and chlorine dioxide $\left(\mathrm{ClO}_{2}\right) \cdot{ }^{24,26-72}$

\section{Hydrogen peroxide}

Hydrogen peroxide was evaluated in its liquid, plasma and gas/vapor forms by nineteen laboratory studies. ${ }^{28,35-39,43,47,53-57,60,61,64,68,70,71}$ The effect of hydrogen peroxide on the filtering capacity varied according to the method used. Hydrogen peroxide plasma led to changes in the masks' metallic nasal clips $^{61}$ and degradation in their filtering performance. ${ }^{37}$ Treatment with liquid hydrogen peroxide caused oxidation of the metal clips $^{37}$ but also inactivated the influenza H1N1 virus. ${ }^{70}$ When used as steam, 
hydrogen peroxide did not leave residual chemical products, ${ }^{57}$ the integrity and filtering capacity of the mask were maintained, ${ }^{28,37,73}$ and the method was effective in eliminating SARS-CoV- $2^{28}$ and spores of Geobacillus stearothermophilus. ${ }^{57}$

\section{Ultraviolet germicidal irradiation (UVGI)}

The effect of ultraviolet germicidal irradiation on $\mathrm{N} 95$ respirators masks was evaluated by 21 studies $24,28,30,33,37,42,45-48,50,51,53,56,58-63,65$ and there was a difference between studies in relation to UVGI doses and application of time periods. In general, UVGI did not affect the integrity and ability of the masks to filter aerosols or adapt to the face, nor did it leave a smell, irritating/toxic residues, or create important changes in appearance even when multiple cycles were performed. $24,28,30,37,42,45,46,48,53,56,60-62$ However, different commercial brands of N95 models resisted differently in terms of performance penetration after multiple cycles and doses applied. ${ }^{46}$ The method was effective against the influenza virus $\mathrm{H} 5 \mathrm{~N} 1,{ }^{24}$ SARS-CoV- $2,{ }^{28}$ bacteriophages MS2, ${ }^{30}$ and influenza virus $\mathrm{H} 1 \mathrm{~N} 1 .{ }^{33,50}$ At the same time, even after 20 min of irradiation with $365 \mathrm{~nm}$ UVA the relative survival of Bacillus subtilis spores remained above $20 \% .{ }^{45}$

\section{Ethylene oxide}

Evaluated by four studies, ${ }^{37,56,60,61}$ the effectiveness of ethylene oxide (EtO) depended on the type of sterilization equipment used, whether there was a hot cycle, and exposure to EtO. The process did not affect the filtration, resistance, odor or appearance of the masks. The main limitations of the method were the processing time and the presence of toxic residues and by-products. None of the studies reported the effectiveness of EtO treatments on microorganisms.

\section{Dry heat}

The use of dry heat was evaluated for by eleven different experimental studies. $27,28,40-42,47,52,59-61,66$ Temperatures between 70 and $85^{\circ} \mathrm{C}$ did not affect the structural characteristics of the masks under various humidity conditions $(\leq 100 \% \mathrm{RH}) .{ }^{28,42}$ The filtering efficiency remained acceptable $(\geq 95 \%)$ up to 50 cycles at $85^{\circ} \mathrm{C}$ and $30 \%$ of $\mathrm{RH}^{42}$ Dry heat at $70^{\circ} \mathrm{C}$ was effective against the SARS-CoV-2 for $1-2$ rounds of decontamination but should not be used for 3 rounds. ${ }^{28}$

\section{Moist heat / pasteurization}

Nine studies $24,26,27,33,37,42,48,49,62$ evaluated the effect of moist heat between 60 and $100^{\circ} \mathrm{C}$. The method did not alter mask fit, odor or comfort. ${ }^{24,33,37,42,62}$ In one study ${ }^{42}$ filtration efficiency has a significant drop after cycle 5 .

Moist heat $\left(65 \pm 5^{\circ} \mathrm{C}\right.$ for $\left.3 \mathrm{~h}\right)$ was also effective in eliminating $\mathrm{H} 1 \mathrm{~N} 1^{33}$ and $\mathrm{H} 5 \mathrm{~N} 1^{24}$ viruses.

\section{Ethanol}


Different methods of decontamination with ethanol were tested: spray, ${ }^{28}$ immersion, ${ }^{31,42,44}$ and pipette drips. ${ }^{45}$ Results were divergent between methods. The filtration efficiency of masks was degraded to unacceptable levels when they were immersed in alcohol. ${ }^{31,42,44}$ Mask filtration performance was not significantly reduced after single ethanol sprays which were also effective in eliminating SARS-CoV-2. ${ }^{28}$ Subsequent rounds of spraying caused sharp drops in filtration performance. ${ }^{28}$ Pipette drips were not effective in eliminating Bacillus subtilis spores. ${ }^{45}$

\section{Isopropanol solution}

The filtering capacity of N95 masks was changed and the particle penetration through the N95 mask exceed $5 \%$ after they had been submerged in isopropanol solution. ${ }^{44,60}$ Effects on microorganisms were not evaluated.

\section{Microwave oven}

Eleven studies tested the use of microwave ovens in the disinfection of N95 masks. ${ }^{24,29,30,33,37,48,52,60-}$ 62,67 . The type of commercial furnace, maximum temperature, and time protocols varied between the studies (Table 3, Supplementary material 4). When masks were placed directly on the rotating plate of the microwave without protection, two commercial models of the tested masks melted. ${ }^{61}$ When the masks were placed in containers with water $24,33,37,62$ or in steam bags specifically marketed for microwave ovens no residual odor was observed. ${ }^{30}$ In addition, there were no structural changes affecting adjustment on the face, filtration capacity, or resistance to airflow and none of the metal components melted or combusted. Microwaving the masks was effective in eliminating H5N1 ${ }^{61}$ and H1N1 influenza viruses $^{62}$ and bacteriophage MS2. ${ }^{30}$

\section{Sodium hypochlorite ( $\mathrm{NaClO}$ )}

Ten studies $29,37,42,44,45,53,56,60,61,63$ evaluated the use of hypochlorite at different concentrations and application methods (Table 3, Supplementary material 4). The maintenance of mask integrity and filtering capacity varied between studies. One study found that one round of disinfection drastically degraded filtration efficiency to unacceptable levels. ${ }^{42} \mathrm{~A}$ second found that application of sodium hypochlorite discolored the metallic components of the masks and left a characteristic smell of bleach. ${ }^{61}$ Finally, one treatment caused the release of low levels of hydrochloric gas. ${ }^{56}$ On the other hand, two studies $^{37,44}$ reported that the method did not affect the filtration or airflow resistance performance of the masks. Only one of the studies tested sodium hypochlorite as a disinfectant, reporting that it was effective in eliminating Bacillus subtilis spores. ${ }^{45}$

\section{Autoclave}

As it is an equipment present in all hospital environments, the autoclave was evaluated by 7 studies with the perspective of being an accessible method. ${ }^{31,32,44,45,60,69,72}$ Autoclave disinfection was effective in 
eliminating Bacillus subtilis spores, ${ }^{45}$ however, had little altered the structural integrity of the masks. ${ }^{44}$

\section{Electric rice cooker}

Despite showing $99-100 \%$ biocide efficacy against Bacillus subtilis ${ }^{45}$ spores after using dry heat for 3minutes (149-164 ${ }^{\circ} \mathrm{C}$, without adding water) and the treatment (for 13-15 minutes, including 8-10 minutes of heating and 5 minutes of steam) also resulted in a greater than 5 log10 reduction in bacteriophage MS2 and methicillin-resistant S aureus. ${ }^{40}$ However, the method visibly changes the mask's integrity. ${ }^{44}$

\section{Cleaning wipes}

The effectiveness of commercial wipes containing $0.9 \%$ hypochlorite, benzalkonium chloride or no active antimicrobial ingredients was evaluated in masks contaminated with Staphylococcus aureus and mucin. ${ }^{34}$ The three mask models withstood handling and abrasion during the disinfection process. All were successfully disinfected against atypically high microbe levels by wipes containing antimicrobial agents but the inert wipes did not produce adequate disinfection.

\section{Bar soap and water}

Average penetration had markedly increased for N95 respirators after being submerged and the authors hypothesized the soap could have removed the charge on the fibers similar to the effect observed with isopropanol solution exposure. ${ }^{60}$

\section{Multi-Purpose High-Level Disinfection Cabinet (Altapure, Mequon, WI)}

The treatment was effective against microorganisms and the researchers reported no visible changes in the masks. However, the efficiency of the filtration has not been confirmed. ${ }^{59}$

\section{Chlorine dioxide $\left(\mathrm{ClO}_{2}\right)$.}

The method significantly changed the filtering efficiency of the tested masks. ${ }^{68}$

\section{Discussion}

Fifteen decontamination methods were identified in the 48 studies $24,26-72$ included in this review. All reports were based on laboratory tests, with ten addressing the infectious capacity of microorganisms and fifteen studying the structural integrity of the masks after the decontamination process.

The studies included in this review used different methodologies. This makes it difficult to summarize the results. This review reveals the inadequacy of the evidence supporting the use of N95 mask decontamination methods. In particular, if the elimination of an organism's infectious capacity has not been proven then a mask that retained its structural integrity is still a potential vehicle of transmission. 
This concern is reinforced by a recent study showing that pathogens may be present on the external surface of about $10 \%$ of used masks, and that the risk of infecting the user increases with prolonged use. ${ }^{74}$ The number of viral particles and their survival time are key determining factors when consideration of reuse becomes necessary. ${ }^{75}$

So far the evidence does not indicate a method that is consistently safe and effective to decontaminate N95 respiratory protection masks. Several of the published results are promising, in particular, hydrogen peroxide vapor, germicidal ultraviolet irradiation, dry heat $\leq 85^{\circ} \mathrm{C}$, moist heat/pasteurization, and microwaving because in the outcomes (filter aerosol penetration, airflow resistance and filtration efficiency) they maintained integrity the integrity of the masks. However, the studies used different decontamination methods, doses and procedures and the most valuable for decision making is to evaluate after which methods the filtration efficiency remained unchanged or within the established thresholds. ${ }^{25}$

In particular, hydrogen peroxide vapor and ultraviolet germicidal irradiation require specific equipment and environments; cost will be a major consideration. Dry heat, wet heat/pasteurization, and microwave ovens also showed positive results in terms of effectiveness and safety and are more accessible methods in scenarios of scarce financial resources. Studies are needed that assess the feasibility of these methods, especially by health systems in developing countries.

The disinfection protocols that used hydrogen peroxide (solution and plasma), ethylene oxide, ethanol, sodium hypochlorite, autoclaves, electric rice cooker, and isopropanol solution interfered with the integrity of the masks within the test conditions used in the studies. Commercial cleaning wipes were effective antimicrobial agents and did not degrade the masks but were only evaluated by a single study and for two microorganisms.

In the case of serious emerging infections such as COVID-19 the principle of universal precaution must be considered, that is, a balance must be made between the benefits and risks of the possible decontamination methods, in order to ensure maximum safety and real protection for the user, especially in the case of two health professionals on the front line. ${ }^{15,76}$

The present study has limitations as, for example, only three databases were searched, given that it was carried out as a quick response in the midst of the COVID-19 pandemic and we adopted a series of methodological simplifications that may affect the findings and our interpretations. Eliminating the evaluation of the studies' methodological qualities was among the simplifications and calls for caution in interpreting the results presented. The strengths of this review, however, are the number of identified methods, the multiple approaches used to search for relevant studies, and the participation of a team of multi-disciplinary specialists in all stages of the project.

\section{Conclusion}


Health care workers on the front lines of pandemics must be guaranteed access to effective PPE. There is currently insufficient evidence to recommend any method as being safe and effective for the decontamination and reuse of respiratory protection masks. There are several promising methods worth further study such as hydrogen peroxide vapor, germicidal ultraviolet irradiation, dry heat at temperatures $\leq 85^{\circ} \mathrm{C}$, wet heat / pasteurization and the microwave oven. However, it is important to emphasize that all need further evaluation and validation in real-life scenarios and with consideration of economic issues of implementation.

\section{List Of Abbreviations}

COVID-19 coronavirus disease

EtO ethylene oxide

SARS-CoV-2 severe acute respiratory syndrome coronavirus 2

PPE Personal Protection Equipment

Influenza A virus subtype H5N1

Influenza virus A subtype H1N1

$\mathrm{NaClO}$ sodium hypochlorite

UVGI Ultraviolet germicidal irradiation

UVA Ultraviolet A

MS2 bacteriophage

WHO World Health Organization

\section{Declarations}

Ethical Approval and Consent to participate Not applicable

Consent for publication Not applicable

Availability of supporting data All data are included in the manuscript

Competing interests The authors declare that they have no competing interests

Funding This study was supported by the Coordenação de Aperfeiçoamento de Pessoal de Nível Superior -Brasil (CAPES)-Finance Code 001.The funding was to translation of the article into English 
Authors' contributions

All authors read and approved the final manuscript

Conceptualization: Livia Fernandes Probst, Andréia Insabralde de Queiroz Cardoso, Ana Tereza Gomes Guerrero, Sandra Maria do Valle Leone de Oliveira.

Investigation: Livia Fernandes Probst, Andréia Insabralde de Queiroz Cardoso, Maria Cristina de Camargo Fonseca, Sandra Maria do Valle Leone de Oliveira, Mariana Croda.

Methodology: Livia Fernandes Probst, Ana Tereza Gomes Guerrero, Andréia Insabralde de Queiroz Cardoso, Mariana Garcia Croda, Sandra Maria do Valle Leone de Oliveira, Antônio José Grande e Jorge Otávio Maia Barreto.

Project administration: Livia Fernandes Probst, Ana Tereza Gomes Guerrero, Andréia Insabralde de Queiroz Cardoso, Sandra Maria do Valle Leone de Oliveira.

Supervision: Jorge Otávio Maia Barreto, Sandra Maria do Valle Leone de Oliveira

Writing - original draft: Livia Fernandes Probst, Andréia Insabralde de Queiroz Cardoso James Venturini, Antonio José Grande

Writing - review \& editing: Sandra Maria do Valle Leone de Oliveira, Anamaria Mello Miranda Paniago, Antônio José Grande, Jorge Otávio Maia Barreto.

Acknowledgements: Staff of the Núcleo de evidência de Mato Grosso do Sul (NEvMS)

Authors' information (optional) not applicable

\section{References}

1. Hui DS. Epidemic and Emerging Coronaviruses (Severe Acute Respiratory Syndrome and Middle East Respiratory Syndrome). Clin Chest Med. 2017;38(1):71-86. doi:10.1016/j.ccm.2016.11.007

2. Sims LD, Domenech J, Benigno $\mathrm{C}$, et al. Origin and evolution of highly pathogenic H5N1 avian influenza in Asia. Vet Rec. 2005;157(6):159-164. doi:10.1136/vr.157.6.159

3. Neumann G, Noda T, Kawaoka Y. Emergence and pandemic potential of swine-origin H1N1 influenza virus. Nature. 2009;459(7249):931-939. doi:10.1038/nature08157

4. Guo Y, Cao Q, Hong Z, et al. The origin, transmission and clinical therapies on coronavirus disease 2019 (COVID-19) outbreak - an update on the status. Mil Med Res. 2020;7(1):11. doi:10.1186/s40779-020-00240-0

5. Zambon M. Influenza and other emerging respiratory viruses. Medicine (Baltimore). 2014;42(1):4551. doi:10.1016/j.mpmed.2013.10.017 
6. Otter JA, Donskey C, Yezli S, Douthwaite S, Goldenberg SD, Weber DJ. Transmission of SARS and MERS coronaviruses and influenza virus in healthcare settings: the possible role of dry surface contamination. J Hosp Infect. 2016;92(3):235-250. doi:10.1016/j.jhin.2015.08.027

7. Long Y, Hu T, Liu L, et al. Effectiveness of N95 respirators versus surgical masks against influenza: A systematic review and meta-analysis. J Evid Based Med. 2020;2(February):jebm.12381. doi:10.1111/jebm.12381

8. Bartoszko JJ, Farooqi MAM, Alhazzani W, Loeb M. Medical Masks vs N95 Respirators for Preventing COVID-19 in Health Care Workers A Systematic Review and Meta-Analysis of Randomized Trials. Influenza Other Respi Viruses. Published online April 4, 2020:0-3. doi:10.1111/irv.12745

9. Jefferson T, Del Mar CB, Dooley L, et al. Physical interventions to interrupt or reduce the spread of respiratory viruses. Cochrane Database Syst Rev. 2011;(7). doi:10.1002/14651858.CD006207.pub4

10. Zhang Z, Liu S, Xiang M, et al. Protecting healthcare personnel from 2019-nCoV infection risks: lessons and suggestions. Published online 2020:2019-2021.

11. Care C, Medicine S, Mahavir V, College M. COVID-19 in intensive care. Some necessary steps for health care workers. 2020;90:161-162. doi:10.4081/monaldi.2020.1284

12. Xiang Y. Tribute to health workers in China: A group of respectable population during the outbreak of the COVID-19. Published online 2020:19-20. doi:10.7150/ijbs.45135

13. Willsher K, Borger J, Holmes O. US accused of "modern piracy" after diversion of masks meant for Europe. The Guardian. https://www.theguardian.com/world/2020/apr/03/mask-wars-coronavirusoutbidding-demand. Published 2020.

14. Whalen J, Morris L, Hamburger T, McCoy T. White House scrambles to scoop up medical supplies worldwide, angering Canada, Germany. The Washington Post.

https://www.washingtonpost.com/business/2020/04/03/white-house-scrambles-scoop-up-medicalsupplies-angering-canada-germany/. Published 2020.

15. Rubio-romero JC, Pardo-ferreira MC, García JAT, Calero-Castro S. Disposable masks: Disinfection and sterilization for reuse, and non-certified manufacturing, in the face of shortages during the COVID-19 pandemic. Safety. 2020;(January). doi:10.1016/j.ssci.2020.104830

16. Chan KH, Yuen K. COVID-19 epidemic: disentangling the re-emerging controversy about medical facemasks from an epidemiological perspective. Published online 2020:1-4. doi:10.1093/ije/dyaa044

17. World Health Organisation (WHO). Rapid reviews to strengthen health policy and systems: a practical guide. Andrea C. Tricco EVL and SES, ed. Published online 2017:119. https://www.who.int/alliancehpsr/resources/publications/rapid-review-guide/en/

18. Rodriguez-Martinez CE, Sossa-Briceño MP, Cortés JA. Decontamination and reuse of N95 filtering facemask respirators: A systematic review of the literature. Am J Infect Control. Published online July 2020. doi:10.1016/j.ajic.2020.07.004

19. Scully C, Samaranayake L. Emerging and changing viral diseases in the new millennium. Oral Dis. 2016;22(3):171-179. doi:10.1111/odi.12356

Page $12 / 19$ 
20. Middleton J, Lopes H, Michelson K, Reid J. Planning for a second wave pandemic of COVID-19 and planning for winter. Int J Public Health. 2020;7. doi:10.1007/s00038-020-01455-7

21. Wise J. Covid-19: Risk of second wave is very real, say researchers. BMJ. 2020;369(June):m2294. doi:10.1136/bmj.m2294

22. Haby MM, Chapman E, Clark R, Barreto J, Reveiz L, Lavis JN. Designing a rapid response program to support evidence-informed decision-making in the Americas region: using the best available evidence and case studies. Implement Sci. 2015;11(1):117. doi:10.1186/s13012-016-0472-9

23. Ouzzani M, Hammady H, Fedorowicz Z, Elmagarmid A. Rayyan-a web and mobile app for systematic reviews. Syst Rev. 2016;5(1):210. doi:10.1186/s13643-016-0384-4

24. Lore MB, Heimbuch BK, Brown TL, Wander JD, Hinrichs SH. Effectiveness of Three Decontamination Treatments against Influenza Virus Applied to Filtering Facepiece Respirators. Ann Occup Hyg. 2011;56(1):92-101. doi:10.1093/annhyg/mer054

25. Qian Y, Willeke K, Grinshpun SA, Donnelly J, Coffey CC. Performance of N95 Respirators: Filtration Efficiency for Airborne Microbial and Inert Particles. Am Ind Hyg Assoc J. 1998;59(2):128-132. doi:10.1080/15428119891010389

26. Anderegg L, Meisenhelder C, Ngooi CO, et al. A scalable method of applying heat and humidity for decontamination of N95 respirators during the COVID-19 crisis. PLoS One. 2020;15(7):e0234851. doi:10.1371/journal.pone.0234851

27. Daeschler SC, Manson N, Joachim K, et al. Effect of moist heat reprocessing of N95 respirators on SARS-CoV-2 inactivation and respirator function. Can Med Assoc J. 2020;192(41):E1189-E1197. doi:10.1503/cmaj.201203

28. Fischer RJ, Morris DH, van Doremalen N, et al. Effectiveness of N95 Respirator Decontamination and Reuse against SARS-CoV-2 Virus. Emerg Infect Dis. 2020;26(9):2253-2255. doi:10.3201/eid2609.201524

29. Fisher E, Rengasamy S, Viscusi D, Vo E, Shaffer R. Development of a Test System To Apply VirusContaining Particles to Filtering Facepiece Respirators for the Evaluation of Decontamination Procedures. App/ Environ Microbiol. 2009;75(6):1500-1507. doi:10.1128/AEM.01653-08

30. Fisher EM, Shaffer RE. A method to determine the available UV-C dose for the decontamination of filtering facepiece respirators. J App/ Microbiol. 2011;110(1):287-295. doi:10.1111/j.13652672.2010.04881.x

31. Grinshpun SA, Yermakov M, Khodoun M. Autoclave sterilization and ethanol treatment of re-used surgical masks and N95 respirators during COVID-19: impact on their performance and integrity. $J$ Hosp Infect. 2020;105(4):608-614. doi:10.1016/j.jhin.2020.06.030

32. Harskamp RE, van Straten B, Bouman J, et al. Reprocessing filtering facepiece respirators in primary care using medical autoclave: prospective, bench-to-bedside, single-centre study. BMJ Open. 2020;10(8):e039454. doi:10.1136/bmjopen-2020-039454

33. Heimbuch BK, Wallace WH, Kinney K, et al. A pandemic influenza preparedness study: Use of energetic methods to decontaminate filtering facepiece respirators contaminated with H1N1 aerosols 
and droplets. Am J Infect Control. 2011;39(1):e1-e9. doi:10.1016/j.ajic.2010.07.004

34. Heimbuch BK, Kinney K, Lumley AE, Harnish DA, Bergman M, Wander JD. Cleaning of filtering facepiece respirators contaminated with mucin and Staphylococcus aureus. Am J Infect Control. 2014;42(3):265-270. doi:10.1016/j.ajic.2013.09.014

35. Ibáñez-Cervantes G, Bravata-Alcántara JC, Nájera-Cortés AS, et al. Disinfection of N95 masks artificially contaminated with SARS-CoV-2 and ESKAPE bacteria using hydrogen peroxide plasma: Impact on the reutilization of disposable devices. Am J Infect Control. 2020;48(9):1037-1041. doi:10.1016/j.ajic.2020.06.216

36. Jatta M, Kiefer C, Patolia H, et al. N95 reprocessing by low temperature sterilization with $59 \%$ vaporized hydrogen peroxide during the 2020 COVID-19 pandemic. Am J Infect Control. Published online June 2020. doi:10.1016/j.ajic.2020.06.194

37. Bergman MS, Viscusi DJ, Heimbuch BK, Wander JD, Sambol AR, Shaffer RE. Evaluation of Multiple (3-Cycle) Decontamination Processing for Filtering Facepiece Respirators. J Eng Fiber Fabr. 2010;5(4):155892501000500. doi:10.1177/155892501000500405

38. Kenney P, Chan B, Kortright K, et al. Hydrogen Peroxide Vapor sterilization of N95 respirators for reuse. 2020;(617):1-6. doi:10.1101/2020.03.24.20041087

39. Levine C, Grady C, Block T, et al. Use, reuse or discard: quantitatively defined variance in the functional integrity of $\mathrm{N} 95$ respirators following vaporized hydrogen peroxide decontamination during the COVID-19 pandemic. J Hosp Infect. Published online October 2020. doi:10.1016/j.jhin.2020.10.007

40. Li DF, Cadnum JL, Redmond SN, Jones LD, Donskey CJ. It's not the heat, it's the humidity: Effectiveness of a rice cooker-steamer for decontamination of cloth and surgical face masks and N95 respirators. Am J Infect Control. 2020;48(7):854-855. doi:10.1016/j.ajic.2020.04.012

41. Li DF, Cadnum JL, Redmond SN, et al. Steam treatment for rapid decontamination of N95 respirators and medical face masks. Am J Infect Control. 2020;48(7):855-857. doi:10.1016/j.ajic.2020.05.009

42. Liao L, Xiao W, Zhao M, et al. Can N95 Respirators Be Reused after Disinfection? How Many Times? ACS Nano. 2020;14(5):6348-6356. doi:10.1021/acsnano.0c03597

43. Lieu A, Mah J, Zanichelli V, Exantus RC, Longtin Y. Impact of extended use and decontamination with vaporized hydrogen peroxide on N95 respirator fit. Am J Infect Control. Published online August 2020. doi:10.1016/j.ajic.2020.08.010

44. Lin T-H, Chen C-C, Huang S-H, Kuo C-W, Lai C-Y, Lin W-Y. Filter quality of electret masks in filtering 14.6-594 nm aerosol particles: Effects of five decontamination methods. Mukherjee A, ed. PLoS One. 2017;12(10):e0186217. doi:10.1371/journal.pone.0186217

45. Lin T-H, Tang F-C, Hung P-C, Hua Z-C, Lai C-Y. Relative survival of Bacillus subtilis spores loaded on filtering facepiece respirators after five decontamination methods. Indoor Air. Published online May 2018. doi:10.1111/ina. 12475

46. Lindsley WG, Martin SB, Thewlis RE, et al. Effects of Ultraviolet Germicidal Irradiation (UVGI) on N95 Respirator Filtration Performance and Structural Integrity. J Occup Environ Hyg. 2015;12(8):509-517. 
doi:10.1080/15459624.2015.1018518

47. Ludwig-Begall LF, Wielick C, Dams L, et al. The use of germicidal ultraviolet light, vaporised hydrogen peroxide and dry heat to decontaminate face masks and filtering respirators contaminated with a SARS-CoV-2 surrogate virus. J Hosp Infect. Published online September 2020. doi:10.1016/j.jhin.2020.08.025

48. Bergman MS, Viscusi DJ, Palmiero AJ, Powell JB, Shaffer RE. Impact of Three Cycles of Decontamination Treatments on Filtering Facepiece Respirator Fit. J Int Soc Respir Prot. 2011;28(1):48-59. https://www.cdc.gov/niosh/nioshtic-2/20039426.html

49. Ma Q-X, Shan H, Zhang C-M, et al. Decontamination of face masks with steam for mask reuse in fighting the pandemic COVID-19: Experimental supports. J Med Virol. Published online April 2020. doi:10.1002/jmv.25921

50. Mills D, Harnish DA, Lawrence C, Sandoval-Powers M, Heimbuch BK. Ultraviolet germicidal irradiation of influenza-contaminated N95 filtering facepiece respirators. Am J Infect Control. 2018;46(7):e49e55. doi:10.1016/j.ajic.2018.02.018

51. Ozog DM, Sexton JZ, Narla S, et al. The Effect of Ultraviolet C Radiation Against Different N95 Respirators Inoculated with SARS-CoV-2. Int J Infect Dis IJID Off PubI Int Soc Infect Dis. Published online September 2020. doi:10.1016/j.ijid.2020.08.077

52. Pascoe MJ, Robertson A, Crayford A, et al. Dry heat and microwave-generated steam protocols for the rapid decontamination of respiratory personal protective equipment in response to COVID-19related shortages. J Hosp Infect. 2020;106(1):10-19. doi:10.1016/j.jhin.2020.07.008

53. Peltier RE, Wang J, Hollenbeck BL, et al. Addressing decontaminated respirators: Some methods appear to damage mask integrity and protective function. Infect Control Hosp Epidemiol. Published online July 2020:1-3. doi:10.1017/ice.2020.332

54. Russo R, Levine C, Veilleux C, et al. Decontaminating N95 respirators during the Covid-19 pandemic: simple and practical approaches to increase decontamination capacity, speed, safety and ease of use. medRxiv Prepr Serv Heal Sci. Published online August 2020. doi:10.1101/2020.08.17.20177022

55. Saini V, Sikri K, Batra SD, Kalra P, Gautam K. Development of a highly effective low-cost vaporized hydrogen peroxide-based method for disinfection of personal protective equipment for their selective reuse during pandemics. Gut Pathog. 2020;12:29. doi:10.1186/s13099-020-00367-4

56. Salter WB, Kinney K, Wallace WH, Lumley AE, Heimbuch BK, Wander JD. Analysis of residual chemicals on filtering facepiece respirators after decontamination. J Occup Environ Hyg. 2010;7(8):437-445. doi:10.1080/15459624.2010.484794

57. Schwartz A, Stiegel M, Greeson N, Vogel A, Thomann W. Decontamination and Reuse of N95 Respirators with Hydrogen Peroxide Vapor to Address Worldwide Personal Protective Equipment Shortages During the SARS-CoV-2 (COVID-19) Pandemic. Appl Biosaf J ABSA Int. Published online 2020. doi:10.1177/1535676020919932

58. Simmons S, Carrion R, Alfson K, et al. Deactivation of SARS-CoV-2 with Pulsed Xenon Ultraviolet: Implications for environmental COVID-19 control. Infect Control Hosp Epidemiol. Published online 
2020:1-4. doi:10.1017/ice.2020.399

59. Cadnum JL, Li D, Redmond SN, John AR, Pearlmutter B, Donskey C. Effectiveness of Ultraviolet-C Light and a High-Level Disinfection Cabinet for Decontamination of N95 Respirators. Pathog Immun. 2020;5(1):52. doi:10.20411/pai.v5i1.372

60. Viscusi DJ, King WP, Shaffer RE. Effect of decontamination on the filtration efficiency of two filtering facepiece respirator models. Int Soc Respir Prot. 2007;24(3/4):93. https://www.isrp.com/the-isrpjournal/journal-public-abstracts/1138-vol-24-no-3-and-no-4-2007-pp-93-107-viscusi-open-access/file

61. Viscusi DJ, Bergman MS, Eimer BC, Shaffer RE. Evaluation of Five Decontamination Methods for Filtering Facepiece Respirators. Ann Occup Hyg. 2009;53(8):815-827. doi:10.1093/annhyg/mep070

62. Viscusi DJ, Bergman MS, Novak DA, et al. Impact of Three Biological Decontamination Methods on Filtering Facepiece Respirator Fit, Odor, Comfort, and Donning Ease. J Occup Environ Hyg. 2011;8(7):426-436. doi:10.1080/15459624.2011.585927

63. Vo E, Rengasamy S, Shaffer R. Development of a test system to evaluate procedures for decontamination of respirators containing viral droplets. App/ Environ Microbiol. 2009;75(23):73037309. doi:10.1128/AEM.00799-09

64. Widmer AF, Richner G. Proposal for a EN 149 acceptable reprocessing method for FFP2 respirators in times of severe shortage. Antimicrob Resist Infect Control. 2020;9(1):88. doi:10.1186/s13756-02000744-3

65. Woo M-H, Grippin A, Anwar D, Smith T, Wu C-Y, Wander JD. Effects of Relative Humidity and Spraying Medium on UV Decontamination of Filters Loaded with Viral Aerosols. Appl Environ Microbiol. 2012;78(16):5781-5787. doi:10.1128/AEM.00465-12

66. Xiang $Y$, Song Q, Gu W. Decontamination of surgical face masks and N95 respirators by dry heat pasteurization for one hour at $70^{\circ} \mathrm{C}$. Am J Infect Control. 2020;48(8):880-882. doi:10.1016/j.ajic.2020.05.026

67. Zulauf KE, Green AB, Nguyen Ba AN, et al. Microwave-Generated Steam Decontamination of N95 Respirators Utilizing Universally Accessible Materials. MBio. 2020;11(3). doi:10.1128/mBio.00997-20

68. Cai C, Floyd EL. Effects of Sterilization With Hydrogen Peroxide and Chlorine Dioxide Solution on the Filtration Efficiency of N95, KN95, and Surgical Face Masks. JAMA Netw Open. 2020;3(6):e2012099. doi:10.1001/jamanetworkopen.2020.12099

69. Carrillo IO, Floyd ACE, Valverde CM, Tingle TN, Zabaneh FR. Immediate-use steam sterilization sterilizes N95 masks without mask damage. Infect Control Hosp Epidemiol. 2020;41(9):1104-1105. doi:10.1017/ice.2020.145

70. Cheng VCC, Wong S-C, Kwan GSW, Hui W-T, Yuen K-Y. Disinfection of N95 respirators by ionized hydrogen peroxide during pandemic coronavirus disease 2019 (COVID-19) due to SARS-CoV-2. J Hosp Infect. 2020;105(2):358-359. doi:10.1016/j.jhin.2020.04.003

71. Cramer A, Plana D, Yang HL, et al. Analysis of SteraMist ionized hydrogen peroxide technology in the sterilization of N95 respirators and other PPE: a quality improvement study. medRxiv Prepr Serv Heal Sci. Published online April 2020. doi:10.1101/2020.04.19.20069997 
72. Czubryt MP, Stecy T, Popke E, et al. N95 Mask Reuse in a Major Urban Hospital - COVID-19 Response Process and Procedure. J Hosp Infect. Published online July 2020. doi:10.1016/j.jhin.2020.07.035

73. Hajifathalian K, Mahadev S, Schwartz RE, et al. SARS-COV-2 infection (coronavirus disease 2019) for the gastrointestinal consultant. World J Gastroenterol. 2020;26(14):1546-1553. doi:10.3748/wjg.v26.i14.1546

74. Chughtai AA, Stelzer-braid S, Rawlinson W, et al. Contamination by respiratory viruses on outer surface of medical masks used by hospital healthcare workers. BMC Infect Dis. 2019;19(491):1-8. doi:10.1186/s12879-019-4109-x

75. Hamzavi IH, Lyons AB, Kohli I, et al. Ultraviolet germicidal irradiation: possible method for respirator disinfection to facilitate reuse during COVID-19 pandemic. J Am Acad Dermatol. Published online April 2020. doi:10.1016/j.jaad.2020.03.085

76. Chughtai AA, Seale H, Islam S, Owais M, Macintyre CR. Policies on the use of respiratory protection for hospital health workers to protect from coronavirus disease ( COVID-19). Int J Nurs Stud. 2020;105(103567). doi:10.1016/j.ijnurstu.2020.103567

77. Banerjee R, Roy P, Das S, Paul MK. A hybrid model integrating warm heat and ultraviolet germicidal irradiation might efficiently disinfect respirators and personal protective equipment. Am J Infect Control. Published online July 2020. doi:10.1016/j.ajic.2020.07.022

78. Burkhart CG. Ozone Disinfectants Like SoClean CPAP Sanitizer can be used to Sterilize Cloth and n95 Masks in the Protection against COVID-19. Open Dermatol J. 2020;14(1):14-15. doi:10.2174/1874372202014010014

79. Ian A, Cabaluna TG, Epi G, Melicor A. What are the effective methods of decontaminating N95 mask for reuse? 2020;2020:1-5.

80. Grossman J, Pierce A, Mody J, et al. Institution of a Novel Process for N95 Respirator Disinfection with Vaporized Hydrogen Peroxide in the Setting of the COVID-19 Pandemic at a Large Academic Medical Center. J Am Coll Surg. 2020;231(2):275-280. doi:10.1016/j.jamcollsurg.2020.04.029

81. Juang PSC, Tsai P. N95 Respirator Cleaning and Reuse Methods Proposed by the Inventor of the N95 Mask Material. J Emerg Med. 2020;58(5):817-820. doi:10.1016/j.jemermed.2020.04.036

82. Lawrence C, Harnish DA, Sandoval-Powers M, Mills D, Bergman M, Heimbuch BK. Assessment of half-mask elastomeric respirator and powered air-purifying respirator reprocessing for an influenza pandemic. Am J Infect Control. 2017;45(12):1324-1330. doi:10.1016/j.ajic.2017.06.034

83. Lowe JJ, Paladino KD, Farke JD, et al. N95 filtering facemask respirator ultraviolet germicidal irridation (uvgi) process for decontamination and reuse. Univ Nebraska Available Here. Published online 2020.

84. Perkins DJ, Villescas S, Wu TH, et al. COVID-19 global pandemic planning: Decontamination and reuse processes for N95 respirators. Exp Biol Med (Maywood). 2020;245(11):933-939. doi:10.1177/1535370220925768

85. Sherwood SC, Dixit V, Salomez C, et al. Final Report for the Bioquell Hydrogen Peroxide Vapor (HPV) Decontamination for Reuse of N95 Respirators. J Phys Chem A. 2011;4(42):10863-10872. 
http://dx.doi.org/10.1016/j.watres.2012.03.036

86. Viscusi DJ, Bergman M, Sinkule E, Shaffer RE. Evaluation of the filtration performance of 21 N95 filtering face piece respirators after prolonged storage. Am J Infect Control. 2009;37(5):381-386. doi:10.1016/j.ajic.2008.09.021

87. Yim W, Cheng D, Patel S, Kui R, Meng YS, Jokerst J V. Assessment of N95 and K95 respirator decontamination: fiber integrity, filtration efficiency, and dipole charge density. medRxiv Prepr Serv Heal Sci. Published online July 2020. doi:10.1101/2020.07.07.20148551

88. Zhong H, Zhu Z, You P, et al. Plasmonic and Superhydrophobic Self-Decontaminating N95 Respirators. ACS Nano. 2020;14(7):8846-8854. doi:10.1021/acsnano.0c03504

\section{Figures}

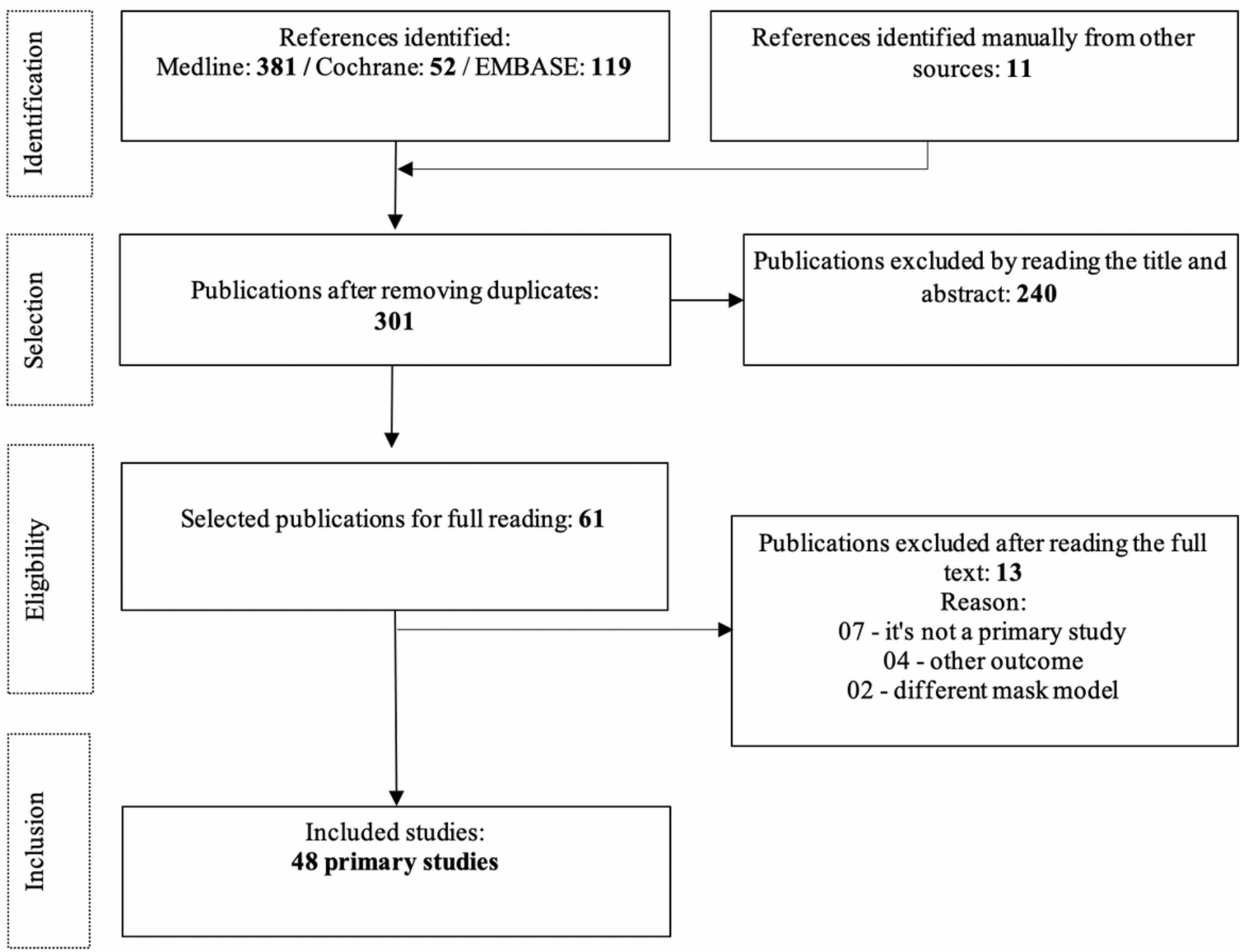

Figure 1

Flowchart of the study selection process 


\section{Supplementary Files}

This is a list of supplementary files associated with this preprint. Click to download.

- PRISMA2009checklist.doc

- RevisedSupplementarymaterial1Protocol.docx

- RevisedSupplementarymaterial3Table2.docx

- RevisedSupplementarymaterial2Table1.docx

- RevisedSupplementarymaterial4Table3.docx

- RevisedSupplementarymaterial5Table4.docx 